\title{
Predictive Value of Zero Calcium Score and Low-End Percentiles for the Presence of Significant Coronary Artery Stenosis in Stable Patients with Suspected Coronary Artery Disease
}

\section{Prädiktiver Wert eines negativen Kalzium-Scores und niedriger Perzentilen für die Präsenz signifikanter koronararterieller Stenosen bei stabilen Patienten mit Verdacht auf koronare Herzkrankheit}

Authors

Affiliations
N. Vogler ${ }^{1}$, M. Meyer ${ }^{1}$, C. Fink ${ }^{2}$, U. J. Schoepf ${ }^{3}$, S. O. Schönberg ${ }^{1}$, T. Henzler ${ }^{1}$

Institute of Clinical Radiology and Nuclear Medicine, University Medical Center Mannheim, Medical Faculty Heidelberg University, Mannheim

Department of Radiology, General Hospital Celle

Department of Radiology and Radiological Science, Medical University of South Carolina, Charleston
Key words

- coronary calcium score

- coronary artery disease

invasive coronary angiography

- coronary CT angiography

eingereicht 20.1.2013

akzeptiert 29.5.2013

Bibliography

DOI http://dx.doi.org/

10.1055/s-0033-1335964

Published online: 2013

Fortschr Röntgenstr 2013; 185:

726-732 @ Georg Thieme

Verlag KG Stuttgart - New York .

ISSN 1438-9029

\section{Correspondence}

\section{Dr. Thomas Henzler}

Institute of Clinical Radiology and Nuclear Medicine,

University Medical Center

Mannheim, Medical Faculty

Heidelberg University

Theodor-Kutzer-Ufer 1-3

68167 Mannheim

Germany

Tel.: ++49/621/3832276

Fax: ++49/621/3833817

thomas.henzler@medma.uni-

heidelberg.de

\section{Zusammenfassung}

v

Ziel: Prospektive Ermittlung des prädiktiven Wertes eines negativen Kalzium-Scores (CS) sowie niedriger geschlechts- und altersspezifischer Perzentilen hinsichtlich der Präsenz signifikanter koronararterieller Stenosen bei stabilen Patienten mit Verdacht auf koronare Herzkrankheit (CAD). Material und Methoden: Insgesamt wurden 87 stabile Patienten mit Verdacht auf CAD (33 Frauen, $66 \pm 10$ Jahre) in diese prospektive Studie eingeschlossen. Alle Patienten erhielten eine native CT zur Messung des Kalk-Scores (CSCT), eine Koronar-CT-Angiografie (CCTA) sowie als Referenzstandard eine invasive Koronarangiografie (ICA). Die diagnostische Genauigkeit des CS hinsichtlich der Präsenz signifikanter Stenosen ( $\geq 50 \%$ Durchmesser) wurde separat im Vergleich zur cCTA und ICA ermittelt.

Ergebnisse: Die ICA zeigte bei 56/87 Patienten (64\%) eine signifikante Stenose. Der mittlere CS betrug $571 \pm 599$. Auf Patientenbasis ergaben sich für Patienten mit einem negativen CS Sensitivität, Spezifität, positiver prädiktiver Wert (PPV) und negativer prädiktiver Wert (NPV) von $98,5 \%, 18,2 \%$, $78,0 \%$ und $80,0 \%$ im Vergleich zur cCTA und $100 \%, 16,1 \%, 68,3 \%$ und $100 \%$ im Vergleich zur ICA. Niedrige, von asymptomatischen Kaukasiern abgeleitete, geschlechts- und altersspezifischen Perzentilen zeigten vergleichbare Ergebnisse.

Schlussfolgerung: Bei stabilen Patienten mit Verdacht auf CAD sind signifikante Stenosen sowohl bei einem negativen CS als auch bei einem Wert unterhalb bestimmter geschlechts- und altersspezifischer Perzentilen selten. Daher sollte der CS bei diesen Patienten als Filter vor Durchführung weiterer diagnostischer Maßnahmen dienen. Ein CSWert unterhalb bestimmter geschlechts- und altersspezifischer Perzentilen scheint bei stabilen Patienten eine dem negativen CS gleichwertige Aussagekraft zu besitzen.

\section{Abstract \\ $\nabla$}

Purpose: To prospectively investigate the predictive value of a zero calcium score (CS) value as well as age- and sex-adjusted low-end CS percentiles for the presence of significant coronary artery stenosis in stable patients with suspected coronary artery disease (CAD).

Materials and Methods: In total, 87 consecutive stable patients with suspected CAD were prospectively enrolled in this study (33 women; 66 \pm 10 years). All patients underwent non-enhanced CT for calcium scoring (CSCT) and contrast-enhanced coronary CT angiography (CCTA). Invasive coronary angiography (ICA) served as the reference standard in all patients. Diagnostic performance for the presence of significant stenosis $(\geq 50 \%$ diameter) was calculated separately for CS in comparison to CCTA and ICA.

Results: ICA identified significant stenosis in 56/ 87 patients (64\%). The mean CS was $571 \pm 599$. On a per patient based analysis, the sensitivity, specificity, positive predictive value (PPV) and negative predictive value (NPV) for patients with a zero CS were $98.5 \%, 18.2 \%, 78.0 \%$ and $80.0 \%$, respectively, compared to cCTA and $100 \%, 16.1 \%$, $68.3 \%$ and $100 \%$, respectively, compared to ICA. Low-end age- and sex-adjusted percentiles derived from asymptomatic Caucasian populations showed results comparable to a CS of zero.

Conclusion: The prevalence of significant coronary artery stenosis is low in stable patients with suspected CAD and a CS of zero but also in patients below certain low-end age- and sex-adjusted percentile ranks. Thus, CS should be used as a gatekeeper prior to further diagnostic procedures in these patients. A CS value below certain ageand sex-adjusted percentile ranks seems to be of identical diagnostic value to a CS of zero in stable patients. 


\section{Introduction}

\section{$\nabla$}

Coronary artery disease (CAD) is known to be the leading cause of death in industrialized countries. In addition, it is a major expense factor in the healthcare systems of industrialized countries. Although there is a necessity to provide decisive diagnostic examinations, performing an invasive coronary angiography (ICA) to detect coronary artery stenosis in all patients with suspected CAD is not appropriate. It has been unequivocally shown that coronary CT angiography (cCTA) is a safe and cost-efficient alternative to rule out coronary artery stenosis in symptomatic patients [1, 2]. Nonetheless, two disadvantages of cCTA are its extensive radiation exposure and its susceptibility to extensive calcification. Although advancement in scanner technology made it possible to substantially reduce the impact of these drawbacks, this is still an issue because 64-row MDCT scanners are currently the most common type of scanner used in cardiac imaging [1, 3 , 4]. Nowadays the radiation exposure of cCTA in general clinical practice is typically in the range of $5-30 \mathrm{mSv}$ with a median radiation exposure of $12 \mathrm{mSv}$ as reported by Hausleiter et al. [5, 6]. There are numerous approaches to reduce overall radiation exposure. For example, Zimmerman et al. suggested using CSCT instead of a conventional scanogram in order to shorten the scan range of cCTA on the z-axis [7]. Another approach would be to restrict the use of CCTA to patients who are more likely to suffer from CAD. This lead to the idea to use non-enhanced CT for calcium scoring (CSCT) as a gatekeeper prior to further diagnostic measures since CSCT in general is associated with a much lower radiation burden than cCTA [8]. Various studies reported that a calcium score (CS) of zero makes the presence of significant coronary artery stenosis very unlikely in asymptomatic stable populations and therefore might be used to rule out significant stenosis $[9-15]$. On the other hand, there are studies that report a non-extraneous prevalence of significant stenosis in symptomatic acute patients with a CS of zero, thus detaining the use of CSCT in this approach [16-19].

The purpose of this study was to evaluate whether a negative CS or low-end percentile ranks adjusted for age and sex lead to a definite conclusion whether CS obtained by dual-source CT is a safe means for ruling out the presence of significant coronary artery stenosis in stable non-acute patients with an intermediate risk for CAD.

\section{Materials and Methods}

\section{$\nabla$}

\section{Study population}

Between October 2009 and August 2011, we prospectively performed CSCT, cCTA and ICA in 90 consecutive patients who presented in our institutional ambulance in stable clinical condition with symptoms suspicious for CAD. Three patients were excluded due to the presence of coronary stents that precluded the possibility to perform CSCT and because CAD was already known. Hence, the final study population comprised 87 patients. All patients were classified as being at intermediate risk for suffering from CAD according to the TIMI risk score [20]. Our institutional review board approved this study. Written informed consent was obtained for all patients and the information gathered was treated according to the Health Insurance Portability and Accountability Act (HIPAA).

\section{CT scanning protocol}

All CT examinations were performed on a $1^{\text {st }}$ generation dualsource CT scanner (SOMATOM Definition, Siemens Healthcare Sector, Forchheim, Germany). Prior to contrast-enhanced cCTA, non-enhanced CSCT was performed in all patients using the following scan parameters: prospective ECG triggering, slice thickness $3 \mathrm{~mm}$ with $50 \%$ overlap, detector collimation $3 \times 64 \times 0.6 \mathrm{~mm}$, gantry rotation time $330 \mathrm{~ms}$, tube current time product $320 \mathrm{mAs}$ per rotation. In patients with a body mass index $(\mathrm{BMI}) \geq 25 \mathrm{~kg} / \mathrm{m}^{2}$, a $120 \mathrm{kV}$ tube potential was used, whereas in patients with a BMI $<25$, the tube potential was reduced to $100 \mathrm{kV}$. For cCTA the scanning technique was chosen individually for each patient depending on heart rate, heart rhythm and BMI to achieve decent image quality while maintaining minimal radiation exposure. The scan techniques included retrospective ECG gating with ECG-dependent tube current modulation and prospective ECG triggering. The acquisition parameters were: $2 \times 32 \times 0.6 \mathrm{~mm}$ detector collimation, gantry rotation time $330 \mathrm{~ms}$, tube current time product $320 \mathrm{mAs}$ per rotation. As in the CSCT protocol, the default tube potential was $120 \mathrm{kV}$, which was reduced to $100 \mathrm{kV}$ in patients with $\mathrm{BMI}<25 \mathrm{~kg} / \mathrm{m}^{2}$. Contrast medium enhancement was achieved by injecting $80 \mathrm{ml}$ of iodinated contrast agent (Imeron 400, Iomeprol $400 \mathrm{mg} \mathrm{I} / \mathrm{ml}$, Bracco Imaging S.p.A., Milano, Italy) at $5 \mathrm{ml} / \mathrm{s}$ through an $18 \mathrm{G}$ intravenous antecubital catheter followed by a $50 \mathrm{ml}$ bolus of saline solution using a dual-syringe injector (Stellant D, Medrad, Indianola, PA). Acquisition was cranio-caudal from above the origin of the coronary arteries to below the dome of the diaphragm.

\section{Image analysis}

The CS derived from the CSCT data sets were calculated by one experienced radiologist using a dedicated software application (Syngo CaScore, Siemens Healthcare Sector, Forchheim, Germany). Besides absolute CS values, we evaluated low-end age- and sex-adjusted percentile ranks derived from asymptomatic Caucasian populations [21, 22].

All cCTA examinations were evaluated by one experienced radiologist for the presence of significant stenosis ( $>50 \%$ lumen diameter) in the coronary artery vessels using the 15-segment model proposed by the American Heart Association [23]. ICA was performed as the reference standard in all patients within an interval not exceeding four months from the CSCT and CCTA examination. ICA was performed according to the conventional Judkins technique with at least two views of the right coronary artery and four views of the left coronary artery. Evaluation for the presence of significant stenosis was accomplished by one experienced cardiologist, using the same 15-segment model.

\section{Statistical analysis}

The statistical analysis was performed using JMP9 (SAS Institute, Cary, North Carolina, USA). Continuous variables were expressed as mean \pm standard deviation (SD). ICA served as the reference standard in all patients. A p-value $<0.05$ was considered significant. All comparisons of mean values were two-tailed. Comparisons between groups were analyzed using the two-tailed student's t-test if data were normally distributed and using the Mann-Whitney U-test if the data were not normally distributed. Dichotomous variables were analyzed using the chi-squared test. Binary classification statistics were used to evaluate the diagnostic performance of CSCT for significant CAD on CCTA and ICA including sensitivity, specificity, positive and negative predictive values for estimated cut-off points. One-on-one comparison of 
CS with significant stenosis on cCTA or ICA, age and gender was performed either with an independent t-test or with a MannWhitney U-test. Receiver operating characteristics (ROC) analysis was performed for CS compared to both CCTA and ICA.

\section{Results}

$\nabla$

\section{Study population}

Patient characteristics are summarized in 0 Table 1. Altogether 87 patients were included in this study. Therefore, a total of 87 patients, 348 vessels and 1305 segments were available for evaluation. All 87 CSCT and ICA examinations were successfully completed. On cCTA diagnostic image quality was found in $97.8 \%$ of all segments. However, in 29 segments (2.2\%) the image quality was considered non-diagnostic and thus the affected segments were considered as positive for the presence of significant stenosis. The participating women were significantly older than the men $(\mathrm{p}=0.0231) .55$ patients $(63 \%)$ had a BMI $\geq 25$. In 29 patients (33\%) the average heart rate was $\geq 75$ beats per minute (bpm).

Prevalence of coronary artery stenosis and calcifications ICA revealed significant stenosis in 56 patients (64.4\%), 91 vessels (26.1\%) and 129 segments (9.9\%). Analysis of the diagnostic ac-

Table 1 Patient characteristics.

Tab. 1 Patientencharakteristika.

\begin{tabular}{|ll|}
\hline men & $54(62 \%)$ \\
\hline women & $33(38 \%)$ \\
\hline mean age & $66 \pm 10(47-86)$ \\
\hline BMI & $28 \pm 5(15-41)$ \\
\hline mean heart rate (bpm) & $74 \pm 17(64-94)$ \\
\hline mean CS (total collective) & $571 \pm 599(0-3,586)$ \\
\hline mean CS (no significant stenosis on ICA) & $358 \pm 499(0-2,146)$ \\
\hline mean CS (significant stenosis on ICA) & $690 \pm 621(2.9-3,586)$ \\
\hline significant stenosis present on ICA & $64.4 \%$ \\
\hline significant stenosis present on cCTA & $74.7 \%$ \\
\hline hypertension & $77 \%$ \\
\hline nicotine abuse & $51 \%$ \\
\hline diabetes mellitus & $24 \%$ \\
\hline dyslipidemia & $43 \%$ \\
\hline family history of cardiovascular disease & $45 \%$ \\
\hline known cardiac arrhythmia ${ }^{1}$ & $34 \%$ \\
\hline
\end{tabular}

Note: $\mathrm{BMI}=$ body mass index; $\mathrm{bpm}=$ beats per minute; $\mathrm{CS}=$ calcium score; $\mathrm{ICA}=$ invasive coronary angiography; $\mathrm{CCTA}=$ coronary $\mathrm{CT}$ angiography.

Anmerkung: $\mathrm{BMI}=$ Body-Mass-Index; bpm = Schläge pro Minute; $\mathrm{CS}$ = Calcium Score; ICA = invasive Koronarangiografie; $c C T A=$ Koronar-CT-Angiografie.

Including atrial fibrillation.

Einschließlich Vorhofflimmern. curacy of cCTA resulted in a sensitivity, specificity, PPV and NPV of $98.2 \%, 67.7 \%, 84.6 \%$, and $95.5 \%$, respectively. All diagnostic accuracy parameters are shown in 0 Table 2 . The mean CS was 571 \pm 599 (range $0-3.586$ ) for all patients. It was significantly higher in patients with significant stenosis $(690 \pm 621$ [range 2.9 $3.586])$ than in patients without significant stenosis $(358 \pm 499$ [range $0-2.146])(p=0.0007) . \diamond$ Fig. 1 exemplarily shows calcification of varying degrees in two study participants. Five patients showed no coronary artery calcification $(C S=0)$ at all.

\section{Diagnostic accuracy of CS}

The diagnostic accuracy of CS in defining significant coronary artery stenosis depends on the chosen CS threshold. All parameters of CS's diagnostic accuracy compared to ICA ( $\bullet$ Table 3 ) and cCTA ( Table 4) are shown for all investigated absolute and percentile-based thresholds.

Compared to ICA, a CS threshold of $\geq 2.9$ provided a sensitivity of $100 \%$, while a CS threshold of $\geq 3586$ provided a specificity of

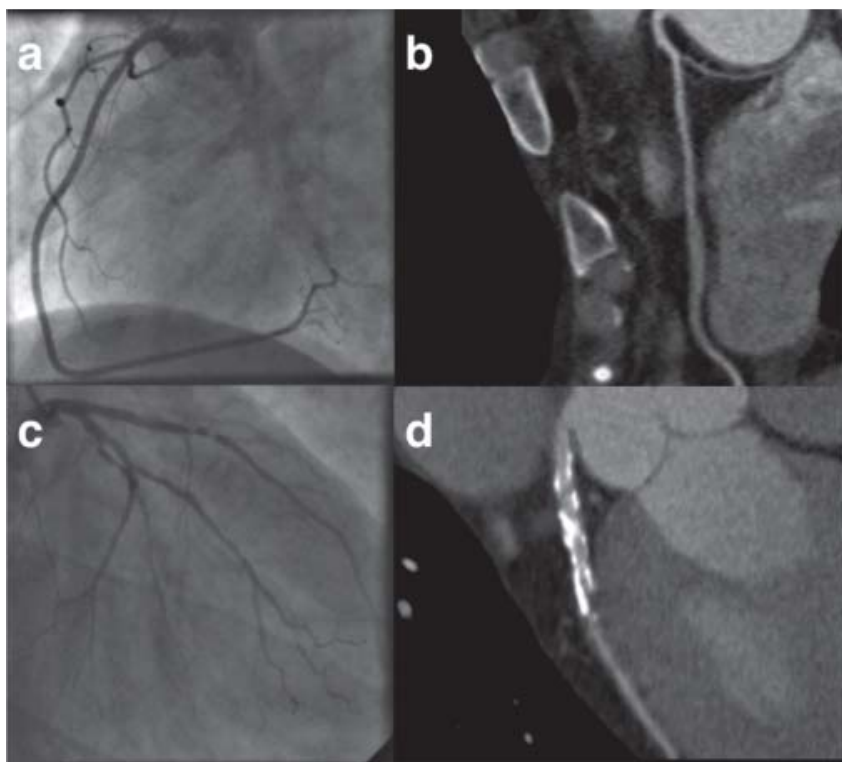

Fig. 1 Calcification to varying degrees in two study participants. Note: ICA $\mathbf{a}$ and $\mathrm{CCTA} \mathbf{b}$ of a non-calcified RCA $(\mathrm{CS}=0)$ in a 52-year-old female patient with no significant stenosis; ICA c and CCTA $\mathbf{d}$ of a distinctly calcified LCA (CS $=1.508)$ in a 71-year-old male patient with significant stenosis.

Abb. 1 Kalzifikationen unterschiedlichen Ausmaßes bei 2 Studienteilnehmern. Anmerkung: ICA a und CCTA b einer nicht kalzifizierten RCA (CS =0) bei einer 52-jährigen weiblichen Patientin ohne signifikante Stenose; ICA c und cCTA d einer ausgeprägt kalzifizierten LCA $(C S=1,508)$ bei einem 71-jährigen männlichen Patienten mit signifikanter Stenose.

Table 2 Diagnostic performance of CCTA for the prediction of significant stenosis on ICA.

Tab. 2 Diagnostische Genauigkeit der cCTA für die Detektion signifikanter Stenosen in der ICA.

\begin{tabular}{|c|c|c|c|c|c|c|c|c|c|c|}
\hline & $\mathbf{n}$ & TP & TN & FP & FN & accuracy \% & sensitivity $\%$ & specificity \% & PPV \% & NPV \% \\
\hline patient & 87 & 55 & 21 & 10 & 1 & $87.4 \%(78.7-89.5)$ & $98.2 \%(91.5-99.9)$ & $67.7 \%(55.6-70.8)$ & $84.6 \%(78.8-86.1)$ & $95.5 \%(78.3-99.8)$ \\
\hline vessel & 348 & 80 & 227 & 36 & 5 & $88.2 \%(84.9-90.0)$ & $94.1 \%(87.2-97.8)$ & $86.3 \%(84.1-97.8)$ & $69.0 \%(63.9-71.6)$ & $97.8 \%(95.3-99.2)$ \\
\hline segment & 1305 & 108 & 1091 & 94 & 12 & $91.9 \%(90.7-92.7)$ & $90.0 \%(83.5-94.4)$ & $92.1 \%(91.4-92.5)$ & $53.5 \%(49.6-56.1)$ & $98.9 \%(98.2-99.4)$ \\
\hline
\end{tabular}

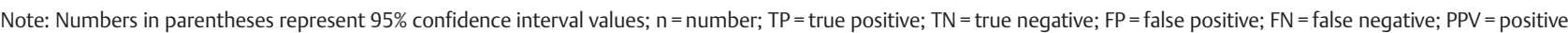
predictive value; NPV = negative predictive value.

Anmerkung: Die Zahlen in Klammern repräsentieren das 95\%-Konfidenzintervall; $n=$ Anzahl; $T P=$ richtig positiv; $T N=$ richtig negativ; $F P=$ falsch positiv; $F N=$ falsch negativ;

PPV = positiver prädiktiver Wert; NPV = negativer prädiktiver Wert. 
Table 3 Diagnostic performance of CS for the prediction of significant stenosis on ICA.

Tab. 3 Diagnostische Genauigkeit des CS für die Detektion signifikanter Stenosen in der ICA.

\begin{tabular}{llllllllllll} 
CS threshold & $\mathbf{n}$ & TP & TN & FP & FN & accuracy $\%$ & sensitivity $\%$ & specificity \% & PPV \% & NPV \% \\
\hline$>0$ & 87 & 56 & 5 & 26 & 0 & $70.1 \%(64.1-70.1)$ & $100 \%(95.3-100)$ & $16.1 \%(7.7-16.1)$ & $68.3 \%(65.1-68.3)$ & $100 \%(47.6-100)$ \\
\hline 10 & 87 & 54 & 8 & 23 & 2 & $71.3 \%(63.5-75.0)$ & $96.4 \%(90.4-99.4)$ & $25.8 \%(14.9-31.1)$ & $70.1 \%(65.7-72.3)$ & $80.0 \%(46.1-96.4)$ \\
\hline$\geq 10^{\text {th } 1}$ & 87 & 56 & 5 & 26 & 0 & $70.1 \%(64.1-70.1)$ & $100 \%(95.3-100)$ & $16.1 \%(7.7-16.1)$ & $68.3 \%(65.1-68.3)$ & $100 \%(47.6-100)$ \\
\hline$\geq 25^{\text {th } 1}$ & 87 & 55 & 6 & 25 & 1 & $70.1 \%(63.3-72.3)$ & $98.2 \%(92.9-99.9)$ & $19.4 \%(9.8-22.4)$ & $68.8 \%(65.1-69.9)$ & $85.7 \%(43.5-99.2)$ \\
\hline$\geq 25^{\text {th } 2}$ & 87 & 56 & 7 & 24 & 0 & $72.4 \%(65.6-72.4)$ & $100 \%(94.7-100)$ & $22.6 \%(13.1-22.6)$ & $70.0 \%(66.3-70.0)$ & $100 \%(57.9-100)$ \\
\hline
\end{tabular}

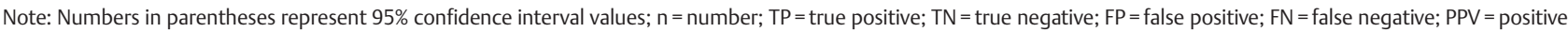
predictive value; NPV = negative predictive value.

Anmerkung: Die Zahlen in Klammern repräsentieren das 95\%-Konfidenzintervall; $n=$ Anzahl; $T P=$ richtig positiv; $T N=$ richtig negativ; $F P=$ falsch positiv; $F N=$ falsch negativ;

PPV = positiver prädiktiver Wert; NPV = negativer prädiktiver Wert.

${ }^{1}$ Percentile for patients with no regular intake of cardiovascular medication according to Schmermund et al. [29].

Perzentile für Patienten ohne regelmäßige Einnahme kardiovaskulär wirksamer Medikamente nach Schmermund et al. [29].

2 Percentile for Caucasian patients according to MESA [30].

Perzentile für Kaukasier nach MESA [30].

Table 4 Diagnostic performance of CS for the prediction of significant stenosis on cCTA.

Tab. 4 Diagnostische Genauigkeit des CS für die Detektion signifikanter Stenosen in der CCTA.

\begin{tabular}{|lllllllllll|}
\hline CS threshold & $\mathbf{n}$ & TP & TN & FP & FN & accuracy $\%$ & sensitivity $\%$ & specificity \% & PPV \% & NPV \% \\
\hline$>0$ & 87 & 64 & 4 & 18 & 1 & $78.2 \%(72.5-80.3)$ & $98.5 \%(94.7-99.9)$ & $18.2 \%(7.0-22.5)$ & $78.0 \%(75.1-79.2)$ & $80.0 \%(30.9-98.9)$ \\
\hline 10 & 87 & 61 & 6 & 16 & 4 & $77.0 \%(69.8-82.9)$ & $93.8 \%(89.0-97.8)$ & $27.3 \%(13.1-38.9)$ & $79.2 \%(75.2-82.5)$ & $60.0 \%(28.8-85.6)$ \\
\hline$\geq 10^{\text {th } 1}$ & 87 & 64 & 4 & 18 & 1 & $78.2 \%(72.5-80.3)$ & $98.5 \%(94.7-99.9)$ & $18.2 \%(7.0-22.5)$ & $78.0 \%(75.1-79.2)$ & $80.0 \%(30.9-98.9)$ \\
\hline$\geq 25^{\text {th } 1}$ & 87 & 63 & 5 & 17 & 2 & $78.2 \%(71.7-81.9)$ & $96.9 \%(92.6-99.4)$ & $22.7 \%(10.0-30.2)$ & $78.8 \%(75.3-80.8)$ & $71.4 \%(31.5-94.8)$ \\
\hline$\geq 25^{\text {th } 2}$ & 87 & 64 & 5 & 17 & 1 & $79.3 \%(73.0-81.5)$ & $98.5 \%(94.3-99.9)$ & $22.7 \%(10.3-27.0)$ & $79.0 \%(75.6-80.2)$ & $83.3 \%(37.9-99.1)$ \\
\hline
\end{tabular}

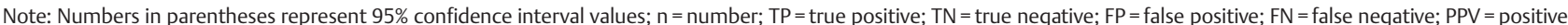
predictive value; NPV = negative predictive value.

Anmerkung: Die Zahlen in Klammern repräsentieren das 95\%-Konfidenzintervall; $n=$ Anzahl; $\mathrm{TP}=$ richtig positiv; $\mathrm{TN}=$ richtig negativ; $\mathrm{FP}=$ falsch positiv; $\mathrm{FN}=$ falsch negativ;

PPV = positiver prädiktiver Wert; NPV = negativer prädiktiver Wert.

${ }^{1}$ Percentile for patients with no regular intake of cardiovascular medication according to Schmermund et al. [29].

Perzentile für Patienten ohne regelmäßige Einnahme kardiovaskulär wirksamer Medikamente nach Schmermund et al. [29].

2 Percentile for Caucasian patients according to MESA [30].

Perzentile für Kaukasier nach MESA [30].

$100 \%$. A CS threshold $\geq 6.6$ provided a sensitivity $(98.2 \%)$ comparable to CCTA but was associated with a much lower specificity $(19.35 \%$ vs. $67.7 \%$ on CCTA). ROC analysis resulted in an area under the curve (AUC) of 0.721 when compared to ICA ( $\bullet$ Fig. 2).

Compared to cCTA, a CS threshold of $>0$ provided a sensitivity of $100 \%$ while a CS threshold of $\geq 3586$ provided a specificity of $100 \%$. In comparison to CCTA, ROC analysis ( Fig. 3 ) showed similar results (AUC $=0.688$ ) as when compared to ICA.

There were no significant differences in sensitivity, specificity and NPV when comparing the diagnostic accuracy of CS to ICA and cCTA (all p > 0.05).

\section{Discussion}

$\nabla$

One of the main purposes of CS is the detection of subclinical stages of CAD, especially in asymptomatic patients at intermediate risk [12]. In this approach a CS of zero results in the exclusion of CAD and in the waiver of further diagnostic measures. In addition, it has been demonstrated that CS is superior to traditional risk factors and clinical risk scores in estimating the risk of experiencing a cardiac event [12, 24]. Moreover, results from recent studies suggest that CSCT is a valuable tool for therapy monitoring [25]. Repeated scans allow conclusions about disease progression and therapy response in the individual patient. High CS values or rapid CS progression provides an indication for intensified treatment of risk factors $[11,12]$. Furthermore, the patient's knowledge of his CS seems to have beneficial effects on lifestyle changes and the use of preventive medical treatment [25].

Currently, in clinical practice the radiation exposure associated with CSCT is about fivefold to tenfold lower than that of CCTA [8]. Due to the ongoing technical development, the effective dose associated with cCTA will continue to drop. If the latest scanner technology is available and the patient fulfills certain requirements (e.g. low BMI and heart rate), low-dose cCTA with a radiation exposure similar to CSCT is feasible [3]. In those cases low-dose cCTA is the method of choice. This is especially true since CS with all potential benefits can be obtained from a cCTA data set [26].

Concerning our study, the relevant application for CS is its diagnostic value to exclude significant stenosis. Elevated CS values are associated with an increased risk for the prevalence of significant stenosis [13]. Depending on the chosen threshold, CS can detect significant stenosis with high sensitivity but only moderate specificity [10-12]. A copious meta-analysis from Sarwar et al. $(n=10355)$ in symptomatic non-acute patients showed a pooled sensitivity, specificity and NPV of $90 \%, 40 \%$ and $93 \%$, respectively, for a CS threshold $>0$. Unfortunately, the NPV values are widely scattered from $68 \%$ up to $100 \%$, depending on the study they are based on [10]. Studies like this led to the conclusion that a negative $\mathrm{CS}(\mathrm{CS}=0)$ is very unlikely to be accompanied by significant coronary artery stenosis, even in symptomatic patients [9]. 


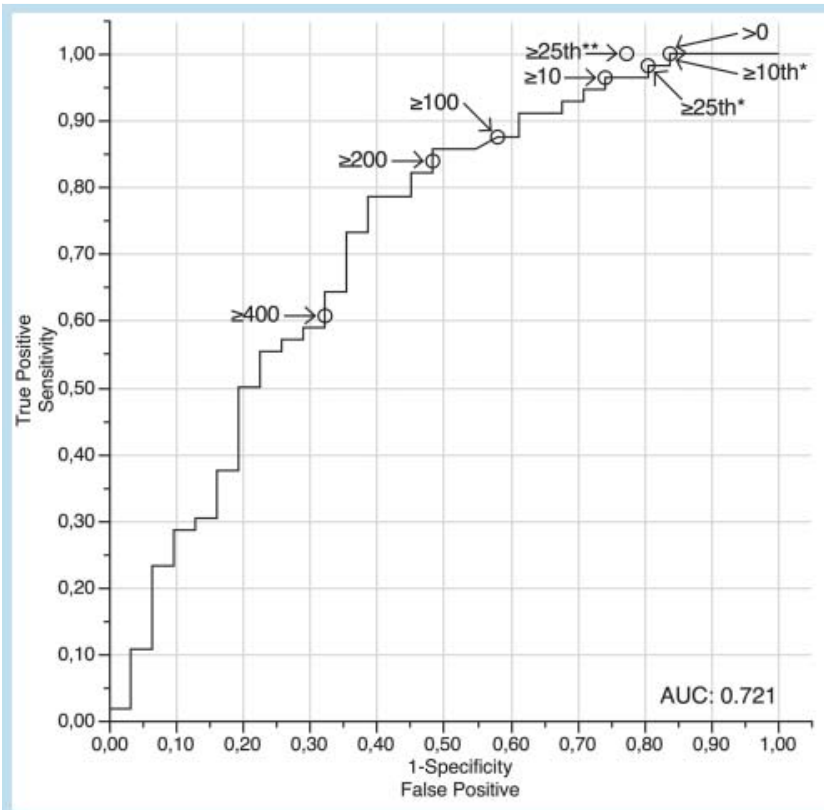

Fig. 2 ROC analysis of CS compared to ICA. Note: Curve represents absolute CS thresholds; AUC = Area under the curve; ${ }^{*}$ percentile for patiens with no regular intake of cardiovascular medication according to Schmermund et al. [29]; * ${ }^{*}$ percentile for Caucasian patients according to MESA [30].

Abb. 2 ROC-Analyse des CS im Vergleich zur ICA. Anmerkung: Der Graph repräsentiert absolute CS-Schwellenwerte; AUC = Fläche unter der Kurve; *Perzentile für Patienten ohne regelmäßige Einnahme kardiovaskulär wirksamer Medikamente nach Schmermund et al. [29]; ** Perzentile für Kaukasier nach MESA [30].

However, it is still controversially discussed whether CSCT is an effective filter prior to further diagnostic measures in symptomatic patients. While some authors like Budoff et al. and Oudkerk et al. support this approach, other authors like Gottlieb et al. and Truong et al. decline the use of CSCT as a filter prior to further diagnostic measures $[11,12,16,17]$. Others authors like Haberl et al. have published contradictory results $[13,18]$. Van Werkhoven et al. suggest that CSCT may be used as a gatekeeper prior to cCTA depending on clinical presentation [19]. In contrast, Uretsky et al. demand further research to determine whether patients with a CS of zero but the presence of plaque represent a group at elevated risk before CSCT can be used as a safe means of exclusion [15]. Since the American College of Cardiology Foundation, the American Heart Association as well as the National Institute for Health and Clinical Excellence regard a negative CSCT as an effective filter prior to further diagnostic measures, we affiliate ourselves with that opinion $[9,27]$. However, it is uncontroversial that even slightly elevated absolute CS thresholds are not reliable in this approach [12]. Furthermore, CSCT is not reliable as a means of exclusion in symptomatic patients at high risk, such as patients suffering from acute coronary syndrome [19].

To further investigate the limits of CS in the exclusion of significant coronary artery stenosis, we evaluated two different percentile systems derived from asymptomatic Caucasian populations, which allowed minor calcification in the elderly (men above 65 years and women above 75 years) without pushing them over the low-end percentile thresholds we chose for evaluation [21, 22 . We consider that a reasonable approach because a 75 -yearold patient's coronary plaques are calcified to a greater extent

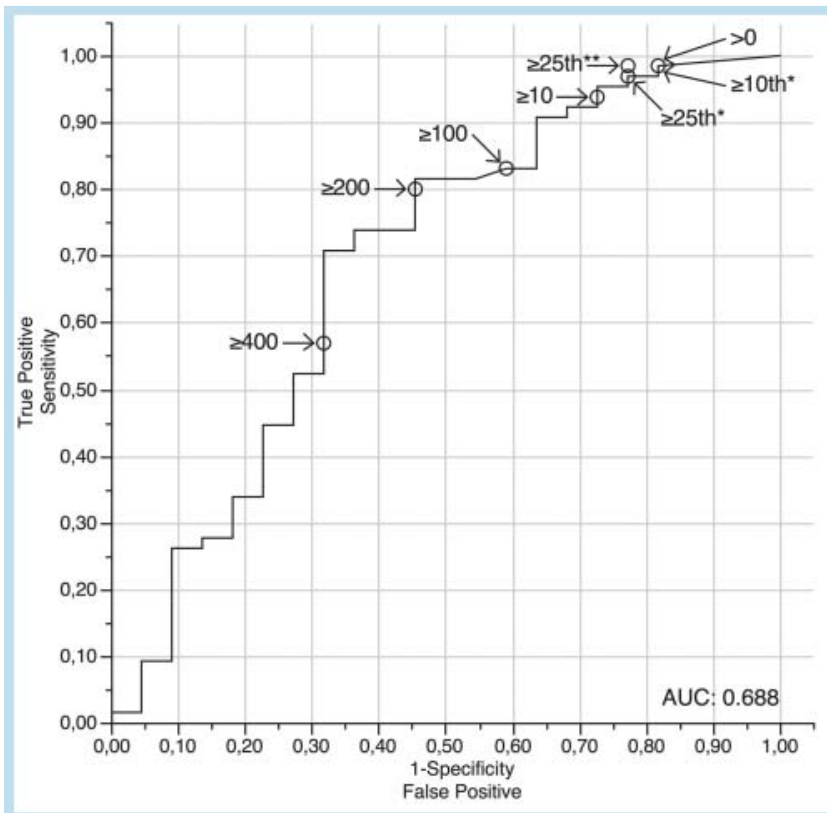

Fig. 3 ROC analysis of CS compared to CCTA. Note: Curve represents absolute CS thresholds; AUC = Area under the curve; ${ }^{*}$ percentile for patients with no regular intake of cardiovascular medication according to Schmermund et al. [29]; ${ }^{*}$ percentile for Caucasian patients according to MESA [30].

Abb.3 ROC-Analyse des CS im Vergleich zur cCTA. Anmerkung: Der Graph repräsentiert absolute CS-Schwellenwerte; AUC = Fläche unter der Kurve; *Perzentile für Patienten ohne regelmäßige Einnahme kardiovaskulär wirksamer Medikamente nach Schmermund et al. [29]; ** Perzentile für Kaukasier nach MESA [30].

than those of a 45-year-old patient [28]. This results in higher absolute CS values in elderly patients compared to younger patients with the same coronary plaque burden. Therefore, an elderly non-acute patient with only minor calcification (e.g. CS=2) is presumably less likely to be affected by significant stenosis than a 45-year-old patient with identical absolute CS. To our knowledge, there is just one study by Akram et al. that ever evaluated low-end age- and sex-adjusted CS percentile ranks in the prediction of significant coronary artery stenosis [29].

Although the AUC values of our study indicate that CS is equally valid for ruling out significant stenosis compared to CCTA (AUC $=0.688$ ) and ICA (AUC $=0.721)$, there are some considerable differences pertaining to other diagnostic accuracy parameters. The accuracy and PPV for a CS threshold of zero and certain percentile thresholds are significantly better when compared to cCTA than to ICA (all $\mathrm{p}<0.05$ ). This has no effect in clinical practice because these parameters are of no interest in the evaluated rule out approach. Under these premises, the NPV is of relevant importance for patient management. The NPV for a CS threshold of zero is just $80 \%$ when compared to cCTA, whereas it is $100 \%$ when compared to ICA. The reason for this is a single segment that was not evaluable on CCTA due to motion artifacts and was therefore considered positive. Because that segment did not show significant stenosis on ICA, it was considered false positive. Due to the small number of patients $(n=87)$, this diminished the NPV to $80 \%$. This NPV value is considerably worse than the NPV published by other authors like Meyer at al. (NPV $=100 \%$ ) and Akram et al. (NPV $=92 \%)[30,31]$. In consequence, the low-end percentile ranks are affected by this coincidence, too. If this non-di- 
agnostic segment, which was negative on ICA, had not been classified as positive, the NPV would have been $100 \%$ as well which would confirm the results of the two studies cited above.

Another noticeable fact concerns the small number of non-diagnostic segments on cCTA. At a mean heart rate of $74 \mathrm{bpm}$, merely $2.2 \%$ of the segments were considered non-diagnostic. This is lower than in some other publications and therefore might not be achievable in general clinical practice, especially at high mean heart rates [32]. This emphasizes the usefulness of ruling out obstructive CAD with CSCT, which is less susceptible to higher heart rates than CCTA.

Our study demonstrates that for a threshold of zero, CS is highly sensitive (100\% compared to ICA) but poorly specific $(16.1 \%$ compared to ICA), which is consistent with the results of other previous studies [12, 33]. For a CS threshold of zero, the NPV is $100 \%$. This supports the thesis that the absence of calcification is convenient to exclude significant stenosis in stable patients with suspected CAD. Interestingly, when using percentile-based thresholds that equal a CS of zero for most patients $\left(\geq 10^{\text {th }}\right.$ percentile according to Schmermund [21] or $\geq 25^{\text {th }}$ percentile according to data from MESA [22]), the NPV was $100 \%$ as well.

Up to now, only minimal data on CS percentile thresholds is available. As a result of a retrospective study by Akram et al. in 210 consecutive asymptomatic and symptomatic patients, the authors stated that absolute CS was superior to MESA percentile rank in predicting obstructive CAD [29]. Though our data indicates the contrary, we do not want to challenge that conclusion in general since it is of no interest concerning the goal of our study. A closer look at the ROC curves by Akram et al. reveals that in their study a CS of zero $(A U C=0.80)$ is indeed superior to the MESA percentile rank $(A U C=0.72)$ in predicting significant stenosis. However, considering only cutoffs with a high sensitivity such as a CS of zero and low-end MESA percentile rank, these thresholds are of identical diagnostic value and thus equally valid for ruling out significant stenosis in asymptomatic as well as symptomatic patients. This is consistent with our results with respect to non-acute patients with suspected CAD.

Another study by Knez et al. in 2115 symptomatic patients using volumetric calcium scoring that evaluated percentile ranks derived from the collective under observance published a sensitivity of $95 \%$ for a threshold $>25^{\text {th }}$ percentile [14]. This rather high sensitivity value is surprising considering that the percentile ranks are derived from symptomatic patients who are likely to have higher CS values, which lead to higher thresholds for the corresponding percentile, thus increasing the risk to include patients suffering from significant coronary artery stenosis in the corresponding low-end percentile.

In knowledge of these results and although our study suggests that low-end percentile ranks may be an effective filter prior to further diagnostic measures and there is no contrary data published, considering the rather small database (data on 221 symptomatic patients published up to now), the exclusion of significant stenosis due to a CS below a low-end percentile rank does not seem appropriately evaluated yet to use it in general clinical practice. Further research on this topic is needed. In contrary, even slightly elevated absolute CS thresholds (e.g. $C S=10$; $\mathrm{NPV}=80.0 \%$ compared to ICA) are not eligible to exclude significant coronary artery stenosis. This finding is equally valid for comparison to ICA and CCTA and is consistent with the results of other studies $[13,14,33]$.

\section{Limitations}

We acknowledge the following limitations to our study. The prevalence of significant coronary artery stenosis in our study (64.4\%) was higher than in other studies investigating CS [13, 14, 33]. The reason might be that some patients objected to ICA after a negative cCTA and therefore had to be excluded from our study. That contingently led to overestimation of sensitivity and underestimation of NPV. Furthermore, we did not collect data on patient ethnicity. Since patient recruitment took place in an urban part of Germany. It is most likely that the vast majority of patients were Caucasian. Because coronary artery calcification is dependent on patient ethnicity, our results may only be applied to Caucasian patients [22].

\section{Conclusion}

Significant coronary artery stenosis is extremely unlikely in stable patients with an intermediate risk of suffering from CAD and a CS of zero. A CS of zero may be used as a gatekeeper prior to further diagnostic procedures in these patients. A CS value below low-end age- and sex-adjusted percentiles $\left(<25^{\text {th }}\right.$ percentile according to MESA; $<10^{\text {th }}$ percentile for patients with no regular intake of cardiovascular medication according to Schmermund etal.) derived from asymptomatic Caucasian populations seems to have identical diagnostic value and thus might be used as a gatekeeper in the future. Since data is currently insufficient to make a reliable statement on diagnostic safety, further research on percentile thresholds is needed.

\section{Acknowledgement}

\section{$\nabla$}

The authors thank the Federal Office for Radiation Protection (BfS) and its staff members for their advice and the financial support of this study.

\section{References}

1 Bastarrika G, Lee YS, Huda W et al. CT of coronary artery disease. Radiology 2009; 253: 317-338

2 Hergan K, Globits S, Loewe C et al. Aktueller Stellenwert der MSCTA in der Koronargefassdiagnostik (2011): Klinischer Leitfaden der Osterreichischen Gesellschaften fur Kardiologie und Radiologie. Fortschr Röntgenstr 2011; 183: 964-971

3 Srichai MB, Lim RP, Donnino R et al. Low-dose, Prospective Triggered High-pitch Spiral Coronary Computed Tomography Angiography: Comparison with Retrospective Spiral Technique. Acad Radiol 2012; 19 (5): 554-561

4 Steinwender G, Szolar D, Preidler K et al. Diagnostische Wertigkeit der kontrastverstarkten MSCT-Koronarangiografie bei Patienten mit hochgradiger Koronarverkalkung im klinischen Alltag. Fortschr Röntgenstr 2011; 183: $1145-1150$

5 Hausleiter J, Meyer T, Hermann F et al. Estimated radiation dose associated with cardiac CT angiography. JAMA: the journal of the American Medical Association 2009; 301: 500-507

6 Fink C, Krissak R, Henzler T et al. Radiation dose at coronary CT angiography: second-generation dual-source CT versus single-source 64MDCT and first-generation dual-source CT. American journal of roentgenology 2011; 196: W550-W557

7 Zimmermann E, Dewey M. Whole-heart 320-row computed tomography: reduction of radiation dose via prior coronary calcium scanning. Fortschr Röntgenstr 2011; 183: 54-59

8 Einstein AJ. Medical imaging: the radiation issue. Nat Rev Cardiol 2009; 6: $436-438$

9 Greenland P, Bonow RO, Brundage BH et al. ACCF/AHA 2007 clinical expert consensus document on coronary artery calcium scoring by computed tomography in global cardiovascular risk assessment and in evaluation of patients with chest pain: a report of the American Col- 
lege of Cardiology Foundation Clinical Expert Consensus Task Force (ACCF/AHA Writing Committee to Update the 2000 Expert Consensus Document on Electron Beam Computed Tomography). Circulation 2007; 115: $402-426$

10 Sarwar A, Shaw LJ, Shapiro MD et al. Diagnostic and prognostic value of absence of coronary artery calcification. JACC Cardiovasc Imaging 2009; 2: 675-688

11 Budoff MJ, Gul KM. Expert review on coronary calcium. Vasc Health Risk Manag 2008; 4: 315 - 324

12 Oudkerk M, Stillman AE, Halliburton SS et al. Coronary artery calcium screening: current status and recommendations from the European Society of Cardiac Radiology and North American Society for Cardiovascular Imaging. Int J Cardiovasc Imaging 2008; 24: 645-671

13 Haberl R, Becker A, Leber A et al. Correlation of coronary calcification and angiographically documented stenoses in patients with suspected coronary artery disease: results of 1,764 patients. Journal of the American College of Cardiology 2001; 37: 451 - 457

$14 \mathrm{Knez} \mathrm{A,} \mathrm{Becker} \mathrm{A,} \mathrm{Leber} \mathrm{A} \mathrm{et} \mathrm{al.} \mathrm{Relation} \mathrm{of} \mathrm{coronary} \mathrm{calcium} \mathrm{scores} \mathrm{by}$ electron beam tomography to obstructive disease in 2,115 symptomatic patients. The American journal of cardiology 2004; 93: $1150-$ 1152

15 Uretsky S, Rozanski A, Singh P et al. The presence, characterization and prognosis of coronary plaques among patients with zero coronary calcium scores. Int J Cardiovasc Imaging 2011; 27: 805-812

16 Gottlieb I, Sara L, Brinker JA et al. CT coronary calcification: What does a score of "0" mean? Curr Cardiol Rep 2011; 13: 49-56

17 Truong $Q$ Kallianos K, Cannon C. Coronary artery disease. Calcium score of zero: not a gatekeeper to rule out coronary artery disease. Rev Cardiovasc Med 2010; 11: 271 - 273

18 Haberl R, Tittus J, Bohme E et al. Multislice spiral computed tomographic angiography of coronary arteries in patients with suspected coronary artery disease: an effective filter before catheter angiography? Am Heart J 2005; 149: 1112 - 1119

19 van Werkhoven JM, de Boer SM, Schuijf JD et al. Impact of clinical presentation and pretest likelihood on the relation between calcium score and computed tomographic coronary angiography. The American journal of cardiology 2010; 106: 1675-1679

20 Antman EM, Cohen M, Bernink PJ et al. The TIMI risk score for unstable angina/non-ST elevation MI: A method for prognostication and therapeutic decision making. JAMA: the journal of the American Medical Association 2000; 284: 835-842

21 Schmermund A, Möhlenkamp S, Berenbein S et al. Population-based assessment of subclinical coronary atherosclerosis using electron-beam computed tomography. Atherosclerosis 2006; 185: 177-182
22 McClelland RL, Chung H, Detrano R et al. Distribution of coronary artery calcium by race, gender, and age: results from the Multi-Ethnic Study of Atherosclerosis (MESA). Circulation 2006; 113: 30-37

23 Austen WG, Edwards JE, Frye RL et al. A reporting system on patients evaluated for coronary artery disease. Report of the Ad Hoc Committee for Grading of Coronary Artery Disease, Council on Cardiovascular Surgery, American Heart Association. Circulation 1975; 51: 5-40

24 Becker A, Leber A, Becker C et al. Predictive value of coronary calcifications for future cardiac events in asymptomatic individuals. Am Heart ] 2008; $155: 154-160$

25 Vliegenthart R, Morris PB. Computed tomography coronary artery calcium scoring: review of evidence base and cost-effectiveness in cardiovascular risk prediction. Journal of thoracic imaging 2012; 27: 296 303

26 Otton JM, Lonborg JT, Boshell D et al. A method for coronary artery calcium scoring using contrast-enhanced computed tomography. J Cardiovasc Comput Tomogr 2012; 6: 37-44

27 Skinner JS, Smeeth L, Kendall JM et al. NICE guidance. Chest pain of recent onset: assessment and diagnosis of recent onset chest pain or discomfort of suspected cardiac origin. Heart 2010; 96: 974-978

28 Stary HC. The development of calcium deposits in atherosclerotic lesions and their persistence after lipid regression. The American journal of cardiology 2001; 88: 16E-19E

29 Akram K, Voros S. Absolute coronary artery calcium scores are superior to MESA percentile rank in predicting obstructive coronary artery disease. Int J Cardiovasc Imaging 2008; 24: 743 - 749

30 Akram K, O'Donnell RE, King $S$ et al. Influence of symptomatic status on the prevalence of obstructive coronary artery disease in patients with zero calcium score. Atherosclerosis 2009; 203: 533-537

31 Meyer M, Henzler T, Fink C et al. Impact of Coronary Calcium Score on the Prevalence of Coronary Artery Stenosis on Dual Source CT Coronary Angiography in Caucasian Patients with an Intermediate Risk. Acad Radiol 2012; 19: 1316-1323

32 Anders $K$, Baum U, Gauss $S$ et al. Erste Erfahrungen mit der sequenziellen, prospektiv getriggerten CT-Koronarangiografie an einem 128Schicht-Computertomografen. Fortschr Röntgenstr 2009; 181: 332 338

33 Leschka S, Scheffel H, Desbiolles L et al. Combining dual-source computed tomography coronary angiography and calcium scoring: added value for the assessment of coronary artery disease. Heart 2008; 94: $1154-1161$ 